\title{
Yöresel Bir Tatlı Olan Ankara Höşmerimi ve Genel Özellikleri Hakkında Nitel Bir Çalışma
}

\author{
A Qualitative Study on a Traditional Dessert: Ankara Höşmerimi and Its General Properties
}

\author{
Alihan TUNCER \\ Yüksek Lisans Öğrencisi \\ alihantuncer06@gmail.com \\ https://orcid.org/0000-0001-9530-8304
}

\author{
Abdullah BADEM \\ Dr. Öğr. Üyesi, Karamanoğlu Mehmetbey Üniversitesi \\ abadem@kmu.edu.tr \\ https://orcid.org/0000-0001-8518-6366
}

Makale Başvuru Tarihi / Received: 06.10.2021

Makale Kabul Tarihi / Accepted: 23.12.2021

Makale Türü / Article Type: Araştırma Makalesi
Anahtar

Ankara

Höșmerimi,

Türk Tatllsı,

Kültürel Miras,

Kültürel Turizm.

\section{ÖZET}

Bir toplumun sahip olduğu maddi ve manevi değerler bütünü, kültür olarak adlandırllmaktadır. Kültür turizmi çok boyutlu bir kavram olup, öğrenme fonksiyonunu temel alarak, insanların düș̈̈nerek yaptıkları ve oluşturdukları unsurları ele almaktadır. Anadolu, tarih boyunca birçok kültüre ve devlete ev sahipliği yapmıştır. Bu kültürlerin kalıntılarını bünyesinde saklayarak gelecek kuşaklara aktarmıştır. Türkler zaman içinde yaşadıkları coğrafyada komșuları ile etkileșim halinde olmuş ve kültür alıșverișinde bulunmuşlardır. Oluşan farklı kültür alışverişleri Ankara'nın mutfak kültürünü ve alışkanlıklarını da yakından etkilemiştir. Bu mutfak kültürünün en çok bilinen lezzetlerinden birisi olan Ankara höşmerimi ev kültüründen çıkarak, yakın zamanda turizm işletmelerinde de yerini almıştır. Bu çalışmada nitel veri analizi kullanılmış olup araştırmaya katılanlar Ankara ilinde ikamet eden evlerinde sılklkla höşmerim yapan on kadından oluşmaktadır. Çalışma Mart-Nisan 2021 tarihlerinde salgından dolayl, telefon görüşmesi yoluyla gerçekleştirilmiştir. Tarihçesi, yapım aşamaları, kullanılan araç ve gereçlerin özelliği hakkında bilgiler derlenmiştir. Bu bilgilerin Ankara mutfak kültürüne katkıda bulunması açısından önem arz edeceği dü̈sünülmektedir. Ayrıca çalışmanın höşmerim üzerine yapılan ilk araștırmalardan olması ve kültürel turizm kaynaklarından olan geleneksel yiyecek ve içeceklerin incelenmesi ile kültür turizminin ülke ekonomisine olan katkısı azımsanmayacak derece fazladır. Turistik bölgede üretilen ve tüketilen yöresel yemeklerin bilinmemesi, unutulmasi o bölgedeki turistik faaliyetlerin azalması veya destinasyon merkezi statüsünden çıkması anlamına gelmektedir. Bu nedenle sürdürülebilir turizmin sağlanabilmesi için yöresel yemek kültürü değerlerinin korunmasl ve sosyokültürel faaliyetler esas alınarak araştırılması önem arz etmektedir. Bu çalı̧̧mada ayrıca, Ankara mutfağında önemli bir yeri olan höşmerim tatlısının yöresel kültür açısından kalite standartları tespit edilmeye çalışılmıştır.
Keywords:

Ankara Höşmerimi, Turkish Dessert, Cultural Heritage, Cultural Tourism.

\begin{abstract}
The material and spiritual values that a society has is called culture. Cultural tourism is a multidimensional concept and deals with the elements that people do and create by thinking, based on the learning function. Anatolia has hosted many cultures and states throughout history. It has kept the remnants of these cultures and passed it on to future generations. Over time, Turks interacted with their neighbors in the geography they lived in and exchanged culture. The different cultural exchanges that have taken place have closely affected the cuisine culture and habits of Ankara. Ankara hösmerimi, one of the most well-known dish of this cuisine culture, has left the home culture and has recently taken its place in tourism businesses and restaurants. Qualitative data analysis was used in this study, and the participants of the study consisted of ten women who frequently reside in Ankara, who made höşmerim in their homes. The study was conducted between March-April 2021 by phone call due to the pandemic. Information about its history, stages of construction, the features of the tools
\end{abstract}


and equipment used were compiled. It is thought that this information will be important in terms of contributing to Ankara cuisine culture. In addition, the contribution of cultural tourism to the economy of the country is considerably high, with the study being one of the first researches on hösmerim and the examination of traditional food and beverages, which are among the cultural tourism resources. Not knowing and forgetting the local food produced and consumed in the touristic region means that the touristic activities in that region are reduced or the destination center status is lost. For this reason, in order to ensure sustainable tourism, it is important to protect the values of local food culture and to research them on the basis of sociocultural activities. In this study, the quality standards of höşmerim dessert, which has an important place in Ankara cuisine, have been tried to be determined in terms of local culture.

\section{GíRiş}

Avrupa ve Asya kıtalarının arasında medeniyetlere köprü olan Anadolu coğrafyası zengin doğal kaynakları, coğrafi konumu ile tarih boyunca medeniyetlerin ilgi odağı olmuş ve birçok millete ev sahipliği yapmıştır. İnsanoğlunun Anadolu'da varlığı Paleolitik çağın başlarına kadar uzanmaktadır. Anadolu'da en erken yerleşme Alt Paleolitik Çă̆'da olduğu, İstanbul'da Küçük Çekmece Gölü'nün yakınında Yarım Burgaz Mağarası'ndan hemen sonra tarihlendiği belirtilmiştir (Sevin, 2013). Paleolitik dönemde yaşayan insanlar iklim şartları, çevre koşullarındaki değişimler sebebiyle besin kaynakları aramak ve avlanmak için konar-göçer yaşam tarzını benimsemişlerdir. Bölge; 12.000 yıllık buğdayın bulunması Anadolu'daki tarımın başladığı bir yerdir. Neolitik çağa gelindiğinde modern insanlığın yaşam tarzının temellerini atacak köklü değişimler gerçekleşmiş, konargöçer yaşam tarzından kalıcı yerleşim yerlerine, avcılık ve toplayıcılıktan üretime, tarım ve hayvancılığa geçiş sağlanmıştır. Modern çağın temellerinin atıldığı bu yaşam biçimi Anadolu'nun çeşitli yerleşim bölgelerinde yaklaşık 4000 yıllık bir gelişim sağlayarak bölgede egemen olmuştur. Sonrasında etkilerini Avrupa da göstermiş ve Avrupa uygarlıklarının oluşumunun temelini atmıştır. Avcı-toplayıcı insanların son izlerini taşıyan aynı zamanda Neolitik çağında ilk ayak seslerinin duyulduğu Göbeklitepe; Son avcı toplayıcı insanlar tarafindan inşası yapılmış, Şanlıurfa'nın Örencik köyünde yer alan dünyadaki en eski yapı topluluğudur. Bölgede gerçekleşen kazılarda keşfedilen 12.000 yıl öncesine ait olan buğday Dünya ve Anadolu'da gastronomi tarihinin başlangıc1 olarak sayılmaktadır. 9000 yıl öncesinde tarımsal üretim ve yerleşik hayatın ilk izlerinin taşıyan Çatalhöyük ise Konya’nın $52 \mathrm{~km}$ güneydoğusunda, Çumra ilçesinin $10 \mathrm{~km}$ doğusunda yer almaktadır. Yapılan kazı ve araştırmalarda bölgenin 5-6 bin kişilik nüfusa sahip olduğu köy veya kasaba olarak nitelendirilebileceği anlaşılmaktadır. Yetiştirdikleri buğdayı öğüterek ekmek yapan, besleyip üremelerini sağladığı hayvanların yaşlı olanlarını pişirerek tüketen insanoğlu Anadolu mutfağının da temellerini atmıştır. M.S. 10. yy’a kadar olan süreçte ise Anadolu'da birçok yerleşim yerleri ve devletler kurulmuş olup bazıları; Hattiler, Hititler ve Urartulardır. Bu uygarlıkların beslenmelerinde tahıl ve tahıl ürünleri ve baklagiller ile koyun, keçi, sığır ve kümes hayvanlarından elde edilen ürünler ana malzemeleri oluşturmuştur. M.S 11.- 14. yy. arasında ise Anadolu Selçukluları ve Beylikler Dönemi görülmüş, bu dönemde Orta Asya'dan getirilen mutfak kültürü, Anadolu' da yerleşik insanların kültürleriyle sentez oluşturmuştur. Osmanlı İmparatorluğu Dönemi ise Osmanlı İmparatorluğu'nun kuruluşundan, Türkiye Cumhuriyeti'nin kuruluşu arasındaki süreçtir. Padişah ve sarayın ileri gelenlerinin hoşuna gidecek yemekleri yapabilmek ve ziyafetleri daha gösterişli hale getirmek için adeta yarışan aşçılar, Osmanlı Mutfak Kültürü'nün zenginleşmesine ciddi katkıda bulunmuşlardır. Cumhuriyet Dönemi ve günümüzde ise ekonomik ve teknolojik gelişmelerle birlikte iletişimin artmasıyla zamanla daha da zenginleştiği söylenmektedir. Değişik yağların ve margarinlerin kullanımı, tatlandırıcı amaçlı bal ve pekmez yerine pancar şekeri kullanılması, unun fraksiyonlarının artması konserve, hazır yemeklerin, gıda katkı maddelerinin ve tatlandırıcıların mutfağa girmesi, yemek pişirme araçlarının değişmesi vb. değişiklikler Geleneksel Mutfak Kültürü'nün değişmesinde rol alan başlıca etmenler olarak sıralanmaktadır (Akın ve ark., 2010).

Bu araştırma ile Ankara'da, genellikle evlerde hazırlanıp pişirilerek yöresel bir yiyecek olarak hazırlanan, bir tatlı olan höşmerimin genel özelliklerinin belirlenmesi ve tanıtılması amaçlanmıştır.

\section{ARAŞTIRMANIN YÖNTEMI}

Çalışmada hedeflere ulaşmak için nitel araştırma yöntemi kullanılmış, konu ile ilgili kaynaklar incelenmiştir. Nitel araştırma gıda ve mutfak kültüründeki beslenme olanaklarını tüm hatları ile araştırmaktır (Harris vd, 2009). Çalışma nitel araştırma yöntemlerinden mülakat/görüşme tekniği ile hazırlanmıştır. Birden fazla katılımcı ile sorucevap şeklinde yapılarak birinci elden bilgi alınmıştır. Mülakat tekniğinin faydalarından birisi görüşme yapılan kişilerin duygu ve düşünceleri net bir şekilde anlaşılabilmesidir (Tekin,2006). Bu araştırmanın amacı Ankara'da genellikle evlerde hazırlanıp pişirilen höşmerimin genel özelliklerinin belirlenmesi ve gastronomik bir değer olarak höşmerimin tanıtılmasıdır. Çalışma Mart 2021 -Nisan 2021 tarihleri arasında yürütülmüştür. Araştırmanın örneklemi, amaçlı örnekleme ile Ankara ilinde ikamet eden ve 25 yaş üstü, höşmerim yapmayı iyi bilen, gönüllü kadınlar arasından seçilen kişiler oluşturmaktadır. Katılımcılar metin içerisinde "kk" şeklinde kullanılmıştır. Bu 
kişilerin arasından sadece gönüllü olan kişilerin seçilmesi sınırlılık yaratmıştır. Görüşmeye katılan katılımcılardan en uygun oldukları gün ve saatte randevu alınarak belirlenen gün ve saatte görüşmeler sağlanmıştır. Görüşmeler ortalama 15-20 dakika arasında gerçekleşmiş. Araştırmada bulguların saptanması için hazırlanan yarı yapılandırılmış görüşme formu kullanılmıştır. Telefonla yapılan görüşmelerin tamamı yazılı ve sesli olarak kayıt altına alınmış ve sonrasında üzerinde çözümlemeler yapılmıştır.

\section{LITERATÜR TARAMASI}

Türk mutfağında yüzyıllar boyunca öneme sahip olan tatlılar, çeşitli ve geleneksel şekilde hazırlanarak tüketime sunulmuştur (Şanlıer, Cömert ve Özkaya Durlu, 2008:1123). Etkileşimde bulunulan devletler ve toplumlar ile zengin bir tatlı kültürü meydana gelmiştir (Diker vd., 2017: 334). Şeker bal ve pekmez gibi tatlandırıcılar Türk Mutfağında yaygın kullanılmıştır. Şeker çok eski zamanlarda Türk mutfağına girdiği bilinmektedir. Mutfakta başlıca kullanımı gerçekleşen şeker temel tüketim malzemesidir. Osmanlı İmparatorluğunda mutfakta yemeklerin ve içeceklerin tatlanması maksadı ile kullanılan şeker, tatlı ve şekerlemelerde de kullanımı sağlanan temel tüketim maddesidir (Ceyhun Sezgin, A. ve Durmaz, P. 2019).

Osmanlı mutfağında ana yemek kadar kıymetlidir tatlılar. Tatlının bulunmadığı sofra yoktur. Ziyafet veya rutin bir yemekte, sofrada muhakkak tatlı bulunmaktadır. Ramazan sofraları çeşitli tatlı çeşitleri ile donatılmaktadır (Türkyılmaz, 2015: 818).

Farklı yapılış biçimlerine sahip olan höşmerim tatlısı ise başta iç Anadolu olmak üzere Balıkesir, Bursa, Konya'da çeşitli formlarda üretilmektedir. Kelime anlamı, Farsçada hoş (tatlı) ve maram (kaymak) sözcüklerinden türeyerek oluşmuştur. Evliya Çelebi'nin seyahat namesinde adı geçen bir tatlıdır. İç Anadolu yöresinde kırsal yerleşimlerde oldukça meşhur bir tatlıdır. Höşmerim Tatlısının diğer illerde üretilen höşmerim tatlılarından farkı malzemeleri arasında peynir ve irmik bulunmamasıdır. Ankara'nın yöresel lezzetlerinde olan Höşmerim tatısının coğrafi işareti, 6769 sayılı Sınai Mülkiyet Kanunu kapsamında 02.07.2020 tarihinden itibaren korunmak üzere 10.03.2021 tarihinde Ankara Ticaret Odası tarafından tescil edilmiştir (www1, 2021).

Mahreç işaretinde belirtilen üretim metodu şu şekildedir:

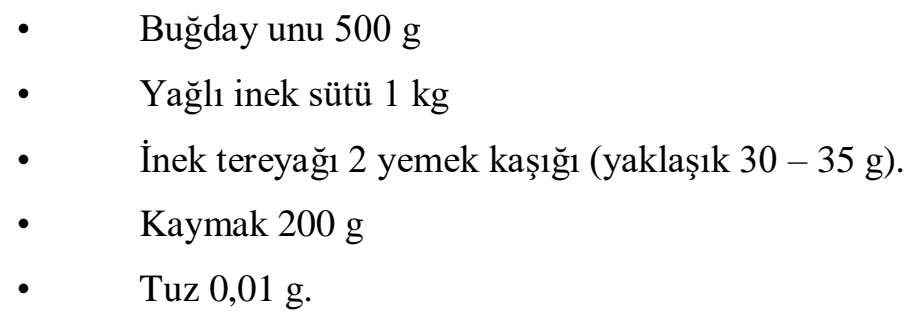

Tencerenin içerisine tereyağı koyulur ve eritilir. Süt ilave edilerek kaynaması beklenir. Kaynayınca yavaş yavaş karıştırılır bir taraftan ise un ilave edilir. Karıştırılırken un, yağ ve sütten homojen bir kıvam elde edilir. Bu işlem kısık ateşte "isıran" ile (yöresel metal bir karıştırıcı) "yedire yedire" (bastıra bastıra) yapılır. Tane tane dökülecek duruma geline kadar karıştırılarak pişirilir. Höşmerimde makbul kıvama gelmesi halk arasında "imiğinde (boğazda) kalmayacak" ifadesiyle tanımlanır. Bu arada tava ara sıra hafifçe sallanır, eğer hamur kalıp halinde sallanmaya başlarsa höşmerim pişmiş sayılır. Pişirilmiş karışım ocaktan alınarak, geniş bir tavaya boşaltılır. Daha sonra tavaya tereyağı koyularak, höşmerim yaklaşık 30 dakika boyunca isıran ile iyice kızarıncaya kadar karıştırılarak pişirilir. Servis edilmesine yakın kısık ateşte birkaç dakika daha beklenir. Sıcakken servis tabağı veya tepsisine ters çevrilip koyularak hazır hale gelir.

Höşmerim isteğe göre servis öncesi üzüm pekmezi, toz şeker veya bal ile tatlandırılabilir. Höşmerim tatlısı servis edilmeden, sıcakken üzerine üzüm pekmezi veya bal sürülür veya toz şeker üzerine serpilebilir. Serpilecek olan şeker, bal ve üzüm pekmezi miktarı tamamen isteğe bağlıdır. 

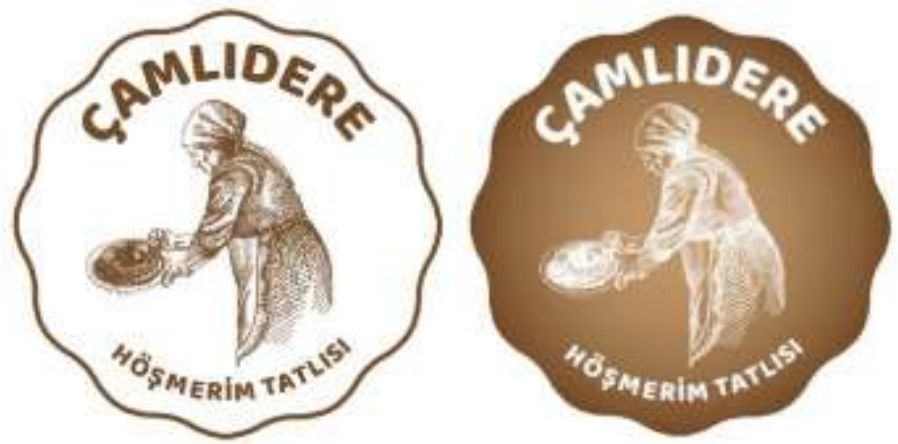

Şekil 1. Çamlıdere Höşmerim Tatlısı ibareli logo ve mahreç işareti amblemi (www2, 2021).

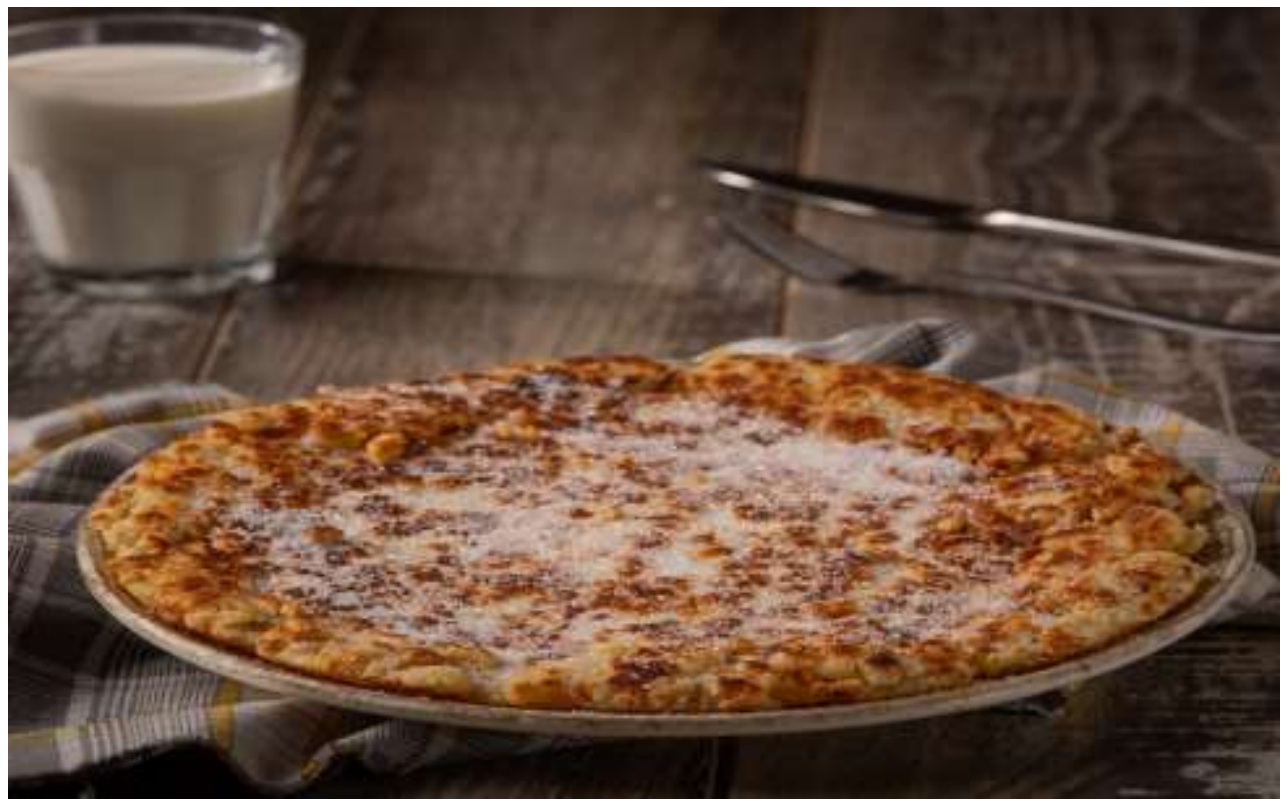

Şekil 2. Höşmerim Tatlısı (www3, 2021).

\section{BULGULAR}

Araştırma Ankara ilinde yaşayan 1965-1996 yılları aralığında doğum tarihine sahip bireyler arasından gerçekleşmiştir. Katılımcılara ait demografik bilgiler Tablo 1'de verilmiştir.

Tablo 1. Katılımcıların demografik özellikleri.

\begin{tabular}{|c|c|c|c|c|}
\hline Kk & İsim Soy isim & Doğum yılı & Memleketi & Cinsiyet \\
\hline 1 & N.A & 1986 & Ankara & Kadın \\
\hline 2 & P.K & 1965 & Ankara & Kadın \\
\hline 3 & S.Y & 1968 & Ankara & Kadın \\
\hline 4 & H.H & 1966 & Ankara & Kadın \\
\hline 5 & G.Y & 1974 & Ankara & Kadın \\
\hline 6 & S.K & 1989 & Ankara & Kadın \\
\hline 7 & F.T & 1995 & Ankara & Kadın \\
\hline 8 & N.Y & 1985 & Ankara & Kadın \\
\hline 9 & G.T & 1968 & Ankara & Kadın \\
\hline 10 & L.I & 1963 & Ankara & Kadın \\
\hline
\end{tabular}


TUNCER, Alihan; BADEM, Abdullah - Yöresel Bir Tatlı Olan Ankara Höşmerimi ve Genel Özellikleri Hakkında Nitel Bir Çalışma (A Qualitative Study on a Traditional Dessert: Ankara Höşmerimi and Its General Properties)

Araştırmada sorulan sorular sıra ile aşağıda verilmiş, veriler düzenlenerek sunulmuştur.

Kaç yıldır höşmerim yapıyorsunuz? sorusu ile ilgili bulgular aşağıda yer almaktadır:

Kat1lımc1lar "6 y1l” (Kk1), "7 y1l” (Kk8), "10 y1l” (Kk6), "15y1l” (Kk3), "18y1l” (Kk7), "20 y1l” (Kk2, Kk5), “25 yıl” (Kk4), "30 y1l” (Kk9) ve "45 yıl”" (Kk10) olarak cevap alınmıştır.

\section{Ne kadar sıklıkla höşmerim yapıyorsunuz? sorusu ile ilgili bulgular aşağıda yer almaktadır:}

Kat1lımc1lar "3-4 ayda bir” (Kk1), "10 günde bir" (Kk2), "misafir geldikçe” (Kk3), "10-15 günde bir” (Kk4), "30 günde bir" (Kk5), "özel gün ve bayramlarda” (Kk6), "2-3 ayda bir” (Kk7, Kk8), "2-2.5 ayda bir” (Kk9, Kk10) yaptıklarını bildirmişlerdir.

Höşmerim tatısını hangi dönemde yaparsınız? Bu dönemin bir özelliği var mıdır? sorusu ile ilgili bulgular aşağıda yer almaktadır:

Katılımcılar "Kalabalık-ağır bir misafir (önemli bir kişi) geldiğinde ve arkadaşlar arasında yaparım" (Kk1), "Düğünlerde bayramlarda, aile bir araya geldiğinde, misafirlere her zaman için yapılabilir." (Kk2), "misafir geldikçe" (Kk3), "Misafir geldiğinde veya ev halkına yaparız." (Kk4), "Düğünlerde bayramlarda, özel bir misafir geldiğinde yapılır." (Kk5), "Özel günlerde ve bayramlarda yaparım.” (Kk6), "Belirli bir dönemi yok ama aileler toplandığında bayramlarda, düğünlerde, ramazan ayında iftardan sonra yapılır." (Kk7), "Misafir geldikçe, çocuklarım istedikçe.” (Kk8), "Ö̈zel misafir geldiğinde günlerde, yakın arkadaşlara." (Kk9), "Misafire daha çok yapılır.”(Kk10) yanıtlarını bildirmişlerdir.

\section{Höşmerim yapılışını kimden/nerden öğrendiniz? sorusu ile ilgili bulgular aşağıda yer almaktadır:}

Katılımcılar "Kayınvalidemden öğrendim.” (Kk1, Kk6), “Annemden ve kayınvalidemden öğrendim.” (Kk2, Kk3), "Annemden ve ablamdan öğrendim." (Kk4), “Annemden öğrendim" (Kk5, Kk7, Kk9 ve Kk10), “Annemden ve Anneannemden öğrendim.” (Kk8) yanıtlarını vermişlerdir.

Höşmerim yapımında kullanılan araç gereçler nelerdir? sorusu ile ilgili bulgular aşağıda yer almaktadır:

Kat1lımcılar "Teflon tava, leğen, kaşık" (Kk1), "Düz tava, isıran" (Kk2, Kk5), "Alüminyum tava, "Zilifli", (Desenli bakır sunum tabağı) 1spatula," (Kk3), "Teflon tava veya alüminyum tava, ıspatula, isıran, höşmerim tabağı, zilifli tabak" (Kk4, "Yayvan tencere' (Basık tencere), tahta kaşık" (Kk6), "Toprak firın, bakır tava, isıran" (Kk7), "Teflon tava, spatula, zilifli düz bakır tabak" (Kk8), "Bazlama tavas1, yayvan tencere, teflon tava, bakır tavada, isıran, veya ıspatula" (Kk9), "Bakır tava, isıran" (Kk10) gibi araç gereçlerin kullanıldığı yönünde bilgi alınmıştır.

\section{Höşmerim yaparken hangi malzemeleri kullanırsınız? sorusu ile ilgili bulgular aşağıda yer almaktadır:}

Katılımcılar "Kaymak, su, yumurta, sıvıyağ, un, kabartma tozu, tuz” (Kk1), "Tereyağı, su, tuz, kaymak, un, şeker” (Kk2), "Kaymak, süt, un, şeker" (Kk3), "Süt, kaymak, tereyağı, un, tuz ve şeker" (Kk4), (Kk5, Kk6, Kk7), "Kaymak, süt, un, tereyağı" (Kk8), "Un, kaymak, süt, su, tuz, tereyağı" (Kk9), "Süt, kaymak, tuz, un, şeker" (Kk10) gibi malzemelerin kullanıldığg yönünde yanıtlar bildirmişlerdir.

\section{Höşmerim yapmak için kullandığınız malzemelerin kendine özgü özellikleri var mı? Sorusuna;}

Katılımcılar "Kaymağ iyi olacak.” (Kk1, Kk2, Kk5), “Alüminyum tava olması tadını güzelleștirir.” (Kk3), “Köy tereyağı ve kaymağı olmalı." (Kk4), "Köy tereyağı, sütü ve kaymağı olmalı.” (Kk6), "Kaymak ve süt güzel olmalı. Sütünde çiğden veya pişmiş olarak koyulması tadını etkiliyor." (Kk7), "Köy tereyağ1 ve kaymağı olacak." (Kk8), "Her türlü kaymak olur." (Kk9), "İnek sütünden iyi olur koyun veya inek kaymağı da olur.” (Kk10) şeklinde görüş bildiriminde bulunmuşlardır.

\section{Höşmerimin yapım aşamalarını anlatır mısınız? sorusu ile ilgili bulgular aşağıda yer almaktadır:}

Katılımcılar "Önce malzemeler bir leğende karıştırılır. Kaymak, su, yumurta sıvıyağ un kabartma tozu ve tuzu karıştırılır, kekten katı bir kıvama getirilir, düz bir tencerede kavrulur, bir tarafı kızarır, ardından tabağa ters çevrilir, tek taraflı kızarması gerekir. Üzerine şeker dökülerek servis edilir" (Kk1), "Köy ocağında ateşin üzerine tava koyulur, bir kaşık tereyağı koyulur, bir çay kaşığı tuz atılır, sütü eklenir, süt kaynadıktan sonra kaymağ1 koyulur. Ardından unu eklenir ve un sütü iyice çeker isıran ile karıştırılarak kızartılır. Tek tarafı kızardıktan sonra höşmerim tabağına alınır. Üzerine şeker serpilir." (Kk2), "Alüminyum tavanın içine süt koyuyoruz süt kaynıyor. Kaymağını koyuyoruz. Kaynadıktan sonra ununu koyuyoruz. Göz göz olup kaynadıktan sonra çevire çevire pişiriyoruz. Çok karıştırınca kum gibi olur. Az çevirirsek kek gibi oluyor. Damak zevkine göre ayarlanır. Kızardıktan sonra üzerine isteğe göre balda dökülür şekerde dökülür. Eskiden '"zilifli'” dediğimiz kapaklı bakır 
tabaklara koyulur servis edilirdi. Şimdi cam servis tabağına koyup servis ediyoruz." (Kk3), "Teflon tava ocağa koyulur, iki su bardağı süt koyulur bir çorba kâsesi krema ve bir çay kaşığı tuz koyulur iki su bardağı un koyulur iyice karıştırılır ve karıştııllarak iyice kızartılır, sonrasında ise düzleştirilerek servis tabağına alınır. Şeker veya bal ile servis edilir." (Kk4), "Tavaya çok az tereyağı koyularak eritilir. Yarım çay bardağı su koyulur. Ardından süt koyulur ve malzemeler kaynayınca tuz atılır. Ardından kaymağı eklenir iyice kaynadıktan sonra unu eklenir. Karıştırılarak kızartılır. Düz bir servis tabağına alındıktan sonra üzerine şeker serpilir.” (Kk5), "İlk önce tereyağını tenceremize alıp eritiyoruz. Daha sonra sütünü ve kaymağını koyuyoruz. Biraz kenarı alıp soğumasını bekliyoruz. Ununu ekleyip "Üğüm üğüm" (tane tane) olana kadar kavuruyoruz. Altını açıp biraz daha kızartıyoruz diğer tarafinı da kızartarak, ters çeviriyoruz. Üzerine toz şeker serpiyoruz." (Kk6), "İlk olarak tavamıza göz kararı tereyağımızı koyuyoruz, kızarmaya başlayınca sütünü ekliyoruz. Sütünü de baya bir kaynatıyoruz, azalmayacak şekilde sonra kaymağını salıyoruz ve iyice bütünleştiriyoruz. En son ununu katıyoruz fakat sürekli karıştırmamız lazım. Hiç durmaksızın karıştırıyoruz. Höşmerimin hamuru kum gibi çok un ufak olmayacak birbirine yapışacak hamuru ve yağıda belli olacak. En son çok az tuz atıyoruz ve isıranla kalıp gibi düzlüyoruz" (Kk7), "Teflon tavanın içine süt koyuyoruz, süt iyice kaynıyor. Kaymağını ekliyoruz. Kaynadıktan sonra ununu ekliyoruz. "Göz göz" (kaynama derecesine ulaşması) olup kaynadıktan sonra kaynadıktan sonra pişiriyoruz. Çok karıştırınca kum gibi olur dikkat etmek gerekir. Damak zevkine göre ayarlanır. Kızardıktan sonra üzerine şeker dökülür. Zilifli dediğimiz kapaklı bakır tabaklara koyulur servis edilirdi." (Kk8), "Tereyağı ve krema eridikten sonra sütü eklenir. Unu eklenir kısık ateşte yapılır. Ters düz edilerek iyice pişirilir. Düz servis tabağına dikkatlice alınır. Üzerine şeker serpilir." (Kk9), "Sütünü koyardık kaymağını koyardık, ısınınca unu atardık, isıranla çevirirdik. Bir fiske tuz atar kızaran kadar iyice çevire çevire pişirirdik. Üzerine de toz şeker atardık." (Kk10) cevaplarını bildirilmiştir.

\section{Höşmerim yapılırken istenilen renk, tat ve lezzet gibi özelliklerin sağlanabilmesi için nelere dikkat edilmesi gerekir? sorusu ile ilgili bulgular aşağıda yer almaktadır:}

Katılımcılar "Kaymağı biraz fazla olmalı, üzerine bolca şeker serpilmeli." (Kk1), "Ne çok kızaracak ne cıvık kalacak bir karar olacak." (Kk2), "Höşmerimin kızarmasına dikkat edilecek. Biraz kızaracak çok kızarınca kum gibi oluyor. Çok hamursu kalmayacak.” (Kk3), "Ne çok kızaracak nede çok sıvı kalacak.” (Kk4, Kk5), "Koyulan un miktarına dikkat edilmeli süte göre un çok olmamalı ve karatmadan kızartılmalı." (Kk6), "Höşmerimi yakmadan sürekli karıştırarak kızartmak önemli. Tereyağın ve kaymağın köyden olması lazım.” (Kk7), "Kısık ateşte kızarmasına dikkat etmek lazım çok karartmadan kızartılmalı." (Kk8), "Unu çok katılırsa "yavan" (yağsız) olur. Özelliği yumuşaklığında. Unu yavaş yavaş ilave edilir." (Kk9), "Unu ne az olacak ne çok olacak unu çok olursa kızarmaz katı olur kaymak çok olacak ki güzelce kızara kızara pişecek." (Kk10) şeklinde yanıtlar alınmıştır.

Höşmerim nasıl servis edersiniz? Kendine özgü bir servis şekli var mı? sorusu ile ilgili bulgular aşağıda yer almaktadır:

Katılımcılar "Düz bakır bir tabakta." (Kk1, Kk5), "Zilifli dediğimiz düz bakır bir tabakta servis ederiz." (Kk2, Kk7), "Kenarları işlemeli zilifli düz bakır tabakta veya cam servis tabağında servis edilir." (Kk3), "Düz bir servis tabağında servis edilir." (Kk6), Güzel yayvan bir tabağa ters çevrilerek servis edilir." (Kk4), "Şeker serpilerek düz bir tabakta servis edilmelidir." (Kk8), "Düz bakır bir tabakta sıcak bir şekilde servis edilir, üzerine ise şeker serpilir.” (Kk9), "Düz bir tabağa servis yapılır.” (Kk10) şeklinde yanıtlar alınmıştır.

Höşmerim muhafaza edilmeye uygun mudur? Nasıl muhafaza edilmelidir? sorusu ile ilgili bulgular aşağıda yer almaktadır:

Katılımcılar "Hemen yemek gerekiyor yenilmezse de üzeri kapatılıp buzdolabında saklanır." (Kk1), "Çok bekletilmemeli 1lık bir şekilde yenilmeli olması gereken yaptığımız budur." (Kk2), "Yiyeceğin kadarını şekerleyebilirsin kalanını da buzdolabına koyup başka zaman bir daha ısıtabilirsin. Toz şekeri ekilmemeli. Şekerlenirse şekerleri yanar. Sadece höşmerimi karıştırıp hiç kızartmadan hamur halde de yapılabiliyor kayınvalidem öyle yapardı." (Kk3), "Çok fazla kızarmadan yarı çiğ durumdayken buzdolabına ayırıp öyle muhafaza edebiliriz." (Kk4, Kk5), "Evet uygundur buzdolabında ağzı kapalı şekilde 3 gün muhafaza ederiz." (Kk6), "Ağzı kapalı bir şekilde buzdolabında olması gerekiyor ağzı açık olursa hamurları kuruyor" (Kk7), "Kapağı kapalı bir kapta şeker dökülmeden 2-3 gün muhafaza edilir." (Kk8), "Hamurunu karıp(yoğurarak) buzlukta beklenirse oradan kızarınca da yeniden yapılır." (Kk10) şeklinde yanıtlar alınmıştır.

Höşmerimin Ankara'da ne zamandan beridir yapıldığı hakkında bilginiz var mı? sorusu ile ilgili bulgular aşağıda yer almaktadır:

Kat1lımcılar "Babaannemde annemde yapard çok eski bir tatlı." (Kk1), "Çok eski zamanlardan beri yapılır gelir." (Kk2), "Kayınvalidemizin zamanından beri yapıldığını biliyorum. Bizim çocukluğumuzda yapılırdı." (Kk3), "Annemizin zamanından beri yapılır. Annem 1950 yılında evlenmiş o zamanlar yapıldığını söylerdi." (Kk4), "Biz 
TUNCER, Alihan; BADEM, Abdullah - Yöresel Bir Tatlı Olan Ankara Höşmerimi ve Genel Özellikleri Hakkında Nitel Bir Çalışma (A Qualitative Study on a Traditional Dessert: Ankara Höşmerimi and Its General Properties)

bizi bildik bileli yapılır. Bizim çocukluğumuzdan beri yapılan çok özel ve kıymetli bir tatlıydı. Bir komşuya imece usulü iş yapmaya gidildiğinde höşmerim ve mercimekli bulgur pilavı yapılırdı." (Kk5), "Kesin bir tarih bilinmiyor ama babaannemin zamanından beri yapılır." (Kk6), "Kuşaktan kuşağa aktarılmış bir tatlı bu tahminim 1900lü yıllardan beri yapılıyor." (Kk7), "1800lü yıllardan beri yapıldığını biliyorum annemin çocukluğunda çok yapılırmış. Anneannemde babaannesinden öğrenmiş. Tahmini 1850 yılına dayanmaktadır.” (Kk8), “Annem babaannesinden görmüş. Çok eski bir tatıdır." (Kk9), "Ebelerimizin dedelerimizin zamanından beri yapılır. Çok eski bir tatll.” (Kk10) şeklinde görüşler bildirilmiştir.

\section{Höşmerim sizin yörenizde yöresel adı/başka bir adı var mı? Höşmerim ile ilgili bir hikâye var mı? sorusu ile ilgili bulgular aşağıda yer almaktadır:}

Katılımcılar "Bir kadının eşi çalışmaya gitmiş, geldiğinde evde hiçbir malzeme yokmuş, kadında unu yağ 1 karıştırmış, tavada pişirmiş, eşi yedikten sonra hoş mu erim demiş ve günümüze de höşmerim olarak gelmiş." (Kk1), "Karı ve koca akşam eve gelmişler ne yapsak demişler, daha sonra kadın höşmerim yapmış, sonrada hoş olmuş mu erim demiş bu şekilde isim türemiş." (Kk2), "Bildiğim bir hikâyesi yok." (Kk3), "Bir bayanın eşi askerden gelmiş, evde olan malzemeleri karıştırmış, tavada pişirmiş, hoş mu erim diyerek servis etmiş, ismi oradan gelmiş." (Kk4), "Bir kadın bu tatlıyı yapmış, tatlının adı yokmuş, eşine ikram etmiş, hoş mu olmuş erim demiş, adı oradan höşmerim olmuş." (Kk5), "Başka ismini duymadım. Hikâye olarak da büyüklerimiz köyde yaşayan bir kadının ineklerini otlamaya göndermiş, yaylaya daha sonra komşusuna gitmiş, oturmuş. Bayağı bir vakit geçmiş, inekler tekrar dönmüş sonrasında kadın yemek yapması gerektiği için, eşinin de gelme vakti yaklaştı̆g için, bir an evvel "katıp karıp" kendince elde bulunan malzemelerden bir yemek hazırlamış, eşine sunmuş, sunarken ise hoş mu erim demiş. Bu zamana kadar böyle gelmiş." (Kk6), "Savaş zamanlarında yokluk çekiyorlarmış köylerde. Kadının kocası askere gitmiş ve çok uzun süre gelmemiş tabi. O zamanda kıtlık var evde bir şey yok, sadece bu tatının malzemeleri kalmış, kadının kocası da gelmiş askerden, kadın ne yapayım diye düşünürken eldeki bu malzemeleri katıp karıştırmış, üzerine de şeker serpmiş. Sunarken ise hoş mu erim demiş, ismi böyle gelmiş." (Kk7), "Çok eski zamanlarda bir adam asker olmuş ve savaşa gitmiş. Uzun yıllar sonra evine dönmüş. Kıtlık zamanı olduğu için evde fazla bir gıda yokmuş. Karısı da unu kaymağı sütü katıp karıştırmış, pişirmiş üzerine de şeker dökmüş. Eşine yerken hoş mu erim demiş, isim oradan türemiş.” (Kk8), "Babaannelerimiz anlatırdı; bir asker evine dönmüş, yemek istemiş, olan malzemelerden bu tatlıyı hazırlamış eşi. Yemeği sunarken hoş mu oldu erim demiş, ismi buradan gelmiş." (Kk9), "Kadının kocası askere gitmiş, askerden gelince evde kaymak kalmış, süt kalmış, bunları karıştırmış, bu tatlıyı yapmış kocasına, hoş mu erim demiş, bu şekilde ismi gelmiş.” (Kk10) şeklinde yanıtlar verilmiştir.

\section{TARTIŞMA VE SONUÇ}

Höşmerim tatlısı, İç Anadolu ve Marmara bölgesinde yapıllyor olmakla beraber araştırma konusunda bahsi geçen çeşidi Ankara İli'nde yapılan Höşmerim tatlısıdır. Yapılan bu araştırmaya göre, Ankara da ilçe ve köy yerleşim yerlerinde halen yaygın olarak yapıldığg ve ilk yapım tarihi ile ilgili net bir bilgi olmamakla birlikte 1850 yıllarına kadar dayandığı bilinmektedir. Literatürde adının Farsçadan "hoş" ve "maram" yani "tatlı" ve "kaymak" kelimelerinden türediği görülmektedir. Adının Farsçadan türemiş olması, net olmamakla birlikte Orta Asya'dan göçler yolu ile taşındığı ve taşınırken ise fars kültüründen etkilendiği, böylelikle İslamiyet sonrası Türk devletlerinden günümüze ulaştığı tahmin edilmektedir.

Çamlıdere Belediye Başkanlığı'nın aldığı mahreç işareti belgesinde Çamlıdere Höşmerimi olarak ismi geçmektedir. İlçeler arasında yapılış şekli bakımından herhangi bir değişiklik göstermemektedir. Höşmerim yapımında yaygın olarak süt, tereyağı, kaymak, tuz ve toz şeker kullanılmaktadır. Nitekim elde edilen bilgiler ve literatür kısmında verilen reçeteler benzerlik göstermektedir. Yapımında kullanılan kaymağın ve tereyağının halis köy kaymağı ve tereyağı olması belirleyici özelliklerinin arasındadır. Ayrıca yapılırken istenilen; dikkat edilmesi gereken noktalar ise; höşmerimin kızarma oranı ve un miktarı olarak ortaya çıkmaktadır. Tatlı çok fazla çevrilerek ve karıştırılarak pişirilirse un ufak olduğu ve toplanmayarak dağıldığı, az karıştırıldığında ise kek formunda kaldığına dikkat çekilmektedir. Yapılan görüşmelerde net bir ölçü verilmediği yapan kişilerin göz ayarıyla ve el oranıyla yaptığı görülmektedir. Katılımcılara yönlendirilen sorular ışı̆̆ında genellikle evlerde özel bir misafir geldiğinde yapıldığı, eski zamanlarda köy yerleşimlerinde daha sık yapıldığı fakat günümüzde şehir yaşamında 2-3 ayda bir yapıldığı bildirilmiştir. Höşmerim yapımında genellikle bakır tava, ikame olarak ise teflon tava kullanılmaktadır. Karıştırmak için yöresel bir hamur kesici olan "isıran” isimli karıştırıcının kullanıldığı bildirilmiştir. Höşmerim tatlısının halen günümüzde düz bakır tabaklarda sunumunun yapıldığı bildirilmiş, ikame olarak cam servis tabaklarının da kullanıldığı belirtilmiştir.

Konya ilinde yapılan höşmerim ile Ankara höşmeriminin reçetesindeki malzemeler benzer olmakla birlikte yapım yönteminde ve servis şeklinde farklılar bulunmaktadır. Ankara höşmeriminde toz şeker tabağa servis edildiğinde 
höşmerimin üzerine serpilmektedir. Fakat Konya höşmeriminde şeker pişirme aşamasında tavadayken ilave edilir ve höşmerimin homojen bir şekilde şekeri çekmesi istenilmektedir.

Balıkesir ilinde yapılan ve Ankara höşmerimi ile sadece isim benzerliği olan yapılış tarzı ve reçetesi bakımından farklılıklar arz eden höşmerim tatlısı Bursa ve Balıkesir çevresinde yapılıp tüketilmektedir. Balıkesir höşmerimi veya peynir helvası olarak da bilinen bu tatlı, ülkemizin farklı bölgelerindeki illerde yapılan höşmerimler ile reçeteleri arasında farklılıklar taşımaktadır. Tuzsuz taze peynir, şeker, irmik ve tereyağı, yumurta sarısı ile yapılan geleneksel bir tatlıdır.

Ülkemizin çok kültürlü yapısı olması, birçok ülke ve millet ile kültürel ve ekonomik bağının olması bu şekilde atalarımızdan bizlere bırakılan yöresel yemek mirasının korunması, elde tutulması ve unutulmaması için yazılı ve görsel bir şekilde kayıt altına alınması gerekmektedir. Bu sebeple Höşmerim gibi tüm yiyecek ve içeceklerimizin coğrafi işaret ve mahreç ile koruma altına alınması önem arz etmektedir. Bunun yanında gastronomik unsur olarak değerlendirilebileceği ve restoran menülerinde kullanılabilec ĕ̌i düşünülmektedir. Ülkemizde höşmerime benzer yapılan diğer tatlıların araştırılarak daha kapsamlı karşılatırılması yapılmasına imkan çıkacağı düşünülmektedir. Ayrıca uluslararası arenalarda tanıtımı için endüstriyel üretiminin de yapılabileceği düşünülmektedir.

\section{Açıklama}

Bu çalışma 26.05.2021 Tarihinde 2. Turizmde Mimarlik Ve Kültürel Miras Kongresi’nde sözlü bildiri olarak sunulmuştur.

\section{KAYNAKÇA}

Ceyhun Sezgin, A. ve Durmaz, P. (2019). Osmanlı Mutfak Kültüründe Şerbetlerin Yeri ve Tüketimi. Journal of Tourism and Gastronomy Studies, 7, 2, 1499-1518.

Akın, G. , Özkoçak, V. \& Gültekin, T. (2015). Geçmişten Günümüze Geleneksel Anadolu Mutfak Kültürünün Gelişimi . Antropoloji , (30) , 33-52 . DOI: 10.1501/antro_0000000319

Tekin, H.H. (2006). Nitel Araştırma Yönteminin Bir Veri Toplama Tekniği Olarak Derinlemesine Görüşme. Erciyes Üniversitesi Sosyal Bilimler Dergisi, 3, 13, 101-116.

Diker, O., Türker, N., Çetinkaya, A. ve Kaya, F. B. (2017). Geleneksel Türk Tatlısı Olarak Lokum ve Safranbolu Lokumu. Journal of Tourism and Gastronomy Studies, 5, özel say1 2, 333-344.

Harris, J.E., Glesanon, P.M., Sheean, P.M., Boushey, C., Beto, J. ve Bruemmer, B. (2009). An Introduction to Qualitative Research for Food and Nutrition Professionals. Journal of the American Dietetic Assocciation, 109, 80-90.

Sevin, V. (2013). Anadolu Arkeolojisi: Başlangıçtan Persler'e Kadar. İstanbul: Der Yayınları.

Şanlıer, N., Cömert, M. ve Özkaya Durlu, F. (2008). Türk Mutfağındaki Geleneksel Tatlı ve Helvaları Gençlerin Tanıma Durumu. Türkiye 10. Gida Kongresi 21-23 Mayıs 2008, Erzurum.

Türkyılmaz, D. (2015). İzmit'in Tadı: Yiyen Bir, Yemeyen Bin Pişmaniye. Uluslararası Kara Mürsel Alp ve Kocaeli Tarihi Sempozyumu II, 3-5 Nisan 2015, Kocaeli.

www1, (2021). https://www.ci.gov.tr

www2, (2021). https://www.ci.gov.tr/Files/GeographicalSigns/9e071663-5147-432d-b946-cd543ca08d0d.pdf

www3, (2021). https://www.hadibey.com/index.php?route=product/product\&product_id=47

Kaynak Kişiler:

Kaynak Kişi-KK1: N.A., 1986, Haymana, Ankara, Kadın, Görüşme tarihi:16.03.2021

Kaynak Kişi-KK2: P.K., 1965, Haymana, Ankara, Kadın, Görüşme tarihi:21.03.2021

Kaynak Kişi-KK3: S.Y., 1968, Haymana, Ankara, Kadın, Görüşme tarihi: 21.03.2021

Kaynak Kişi-KK4: H.H., 1966, Haymana, Ankara, Kadın, Görüşme tarihi: 21.03.2021

Kaynak Kişi-KK5: G.Y., 1974, Polatl1, Ankara, Kadın, Görüşme tarihi:21.03.2021

Kaynak Kişi-KK6: S.K., 1989, Yenimahalle, Ankara, Kadın, Görüşme tarihi:09.04.2021

Kaynak Kişi-KK7: F.T., 1995, Etimesgut, Ankara, Kadın, Görüşme tarihi:09.04.2021 
TUNCER, Alihan; BADEM, Abdullah - Yöresel Bir Tatlı Olan Ankara Höşmerimi ve Genel Özellikleri Hakkında Nitel Bir Çalışma (A Qualitative Study on a Traditional Dessert: Ankara Höşmerimi and Its General Properties)

Kaynak Kişi-KK8: N.Y., 1985, Polatl1, Ankara, Kadın, Görüşme tarihi:10.04.2021

Kaynak Kişi-KK9: G.T., 1968, Haymana, Ankara, Kadın, Görüşme tarihi:10.04.2021

Kaynak Kişi-KK10: L.İ., 1963, Haymana, Ankara, Kadın, Görüşme tarihi:10.04.2021 